\title{
Environmentally friendly materials of Magnesium oxychloride cement-cornstalk research
}

\author{
Changwei $\mathrm{Xu}^{1, \mathrm{a}}$,Chenjian $\mathrm{Xu^{1,b }}$,Pengpeng Fan ${ }^{1, c}$ \\ ${ }^{1}$ School of Material Science and Engineering,Shenyang Jianzhu University, Shenyang \\ 110168,China

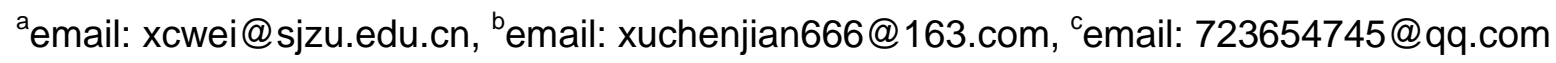

\begin{abstract}
Key words: Magnesium oxychloride cement; cornstalk fibers; crack resistance; toughness
\end{abstract}
Abstract: Magnesium oxychloride cement-cornstalk is an environmentally friendly composite, the major constituent of which is magnesium oxychloride cement(MOC) and cornstalk fibers. In order to obtain composites with excellent performance, phosphoric acid and cornstalk fibers was adopted to MOC modification. The results show that $1.0 \%$ phosphoric acid modification can solve the problem of later strength decline of MOC and improve water resistance by $41 \%$; when the volume ratio of cornstalk fibers reaching 1.0, the workability of mixtures performs well, the crack resistance and toughness of test blocks are enhanced, and the $28 \mathrm{~d}$ bend-press ratio reaches 0.26 ;

\section{Introduction}

As the second largest crop straw, cornstalks mainly distribute in the Huang-Huai-Hai area, accounting for $21.67 \%$ of the total. Cornstalks are characterized by large porosity, lightweight and great corrosion resistance, and its main constituents are hemicellulose, cellulose, lignin and soluble sugar. Since large amount of magnesium resources, coupled with by-product of magnesium chloride from coastal salt industry, Liaoning province has advantages of producing MOC, which is characterized by rapid hardening and strong cohesive force ${ }^{[1-2]}$.

With the combination of MOC and cornstalks, green energy-saving building materials with high strength and salient crack resistance can be obtained. It can be widely used in indoor partition board and interior decorative board.

\section{Materials and testing methods}

Materials. Magnesia powder( $\mathrm{MgO})$ : content is $80 \%$, activity is $65 \%$;Anhydrous magnesium chloride $\left(\mathrm{MgCl}_{2}\right)$ : content is $99 \%$; Cornstalk fibers: length is about $2 \mathrm{~cm}$, the volume ratio of cornstalk involved in this paper refers to the ratio of stacking volume of cornstalk fibers to volume of MOC paste; Phosphoric acid $\left(\mathrm{H}_{3} \mathrm{PO}_{4}\right)$ : content reaches $85 \%$.

Testing methods. Depend on the theoretical chemical reaction equation of MOC system, the mix design of MOC was designed as the molar ratio of materials: active $\mathrm{MgO}: \mathrm{MgCl}_{2}: \mathrm{H}_{2} \mathrm{O}=\mathrm{n}: 1$ : $(\mathrm{n}+$ 8), $\mathrm{n}=\mathrm{MgO} / \mathrm{MgCl}_{2}$, as shown in Table 1. In the end, the mechanical properties and water resistance of MOC would be tested and evaluated. The strength retention rate $\mathrm{K}_{7}$ was evaluated as the evaluation index of water resistance of $\mathrm{MOC}$, defined as $\mathrm{K}_{7}=\mathrm{f} / \mathrm{F} \times 100 \%, \mathrm{~K}_{7}$ refers to the strength retention rate of the test block after soaking for 7 days, f refers to compressive strength after soaking for 7 days and $F$ referred to compressive strength before soaking ${ }^{[3]}$. 
Table1 Mix design of MOC

\begin{tabular}{ccccc}
\hline NO. & $\mathrm{MgO} / \mathrm{MgCl}_{2}$ & $\mathrm{MgO} / \mathrm{g}$ & $\mathrm{MgCl}_{2} / \mathrm{g}$ & $\mathrm{H}_{2} \mathrm{O} / \mathrm{g}$ \\
\hline B-4 & 4 & 248 & 96 & 216 \\
B-5 & 5 & 310 & 96 & 234 \\
B-6 & 6 & 372 & 96 & 252 \\
B-7 & 7 & 434 & 96 & 270 \\
B-8 & 8 & 496 & 96 & 288 \\
B-9 & 9 & 558 & 96 & 306 \\
\hline
\end{tabular}

In order to stabilize $5 \cdot 1 \cdot 8$ phases, reform the pore structure of cement and enhance water resistance, MOC above based on the optimum mix design was modified by phosphoric acid. The influence of phosphoric acid on the mechanical properties and water resistance of MOC has been researched.

Add cornstalk to the modified MOC, as showed in Table 2. The apparent density $\left(\rho_{0}\right)$, compressive strength $\left(R_{s}\right)$ and bending strength $\left(R_{f}\right)$ of $28 d$ were tested respectively, specific strength and bend-press ratio were calculated.

Table 2 Mix proportion design of MOC-cornstalk

\begin{tabular}{cccccc}
\hline $\mathrm{NO}$. & $\mathrm{MgO} / \mathrm{g}$ & $\mathrm{MgCl}_{2} / \mathrm{g}$ & $\mathrm{H}_{2} \mathrm{O} / \mathrm{g}$ & $\mathrm{H}_{3} \mathrm{PO}_{4} / \mathrm{g}$ & volume ratio of cornstalk \\
\hline $\mathrm{C}-1$ & 1116 & 288 & 756 & 11.6 & 0.50 \\
$\mathrm{C}-2$ & 1116 & 288 & 756 & 11.6 & 0.75 \\
$\mathrm{C}-3$ & 1116 & 288 & 756 & 11.6 & 1.00 \\
$\mathrm{C}-4$ & 1116 & 288 & 756 & 11.6 & 1.25 \\
$\mathrm{C}-5$ & 1116 & 288 & 756 & 11.6 & 1.50 \\
$\mathrm{C}-6$ & 1116 & 288 & 756 & 11.6 & 1.75 \\
$\mathrm{C}-7$ & 1116 & 288 & 756 & 11.6 & 2.00 \\
\hline
\end{tabular}

\section{Test results and analysis}

Mix proportion of MOC. From Table 3, MOC with different mix design had the characteristic of high early strength. Nevertheless, the test block compressive strength of $28 \mathrm{~d}$ appeared obvious decline with the growth of the age. According to some investigator, strength decline is caused by crystal stress and transition of the crystal phase $(5 \cdot 1 \cdot 8$ phase transition to $3 \cdot 1 \cdot 8$ phase $)$.

From Table 4, the compressive strength of test blocks declined after soaking, B-8 and B-9 test blocks were cracked after soaking. First of all, $5 \cdot 1 \cdot 8$ phases and $3 \cdot 1 \cdot 8$ phases are unstable in polar solvents, especially in water. Therefore, MOC has a tendency to dissolve and hydrolyze after affecting by polar water molecules, which result in the decline of MOC strength ${ }^{[7]}$. Secondly, excessive $\mathrm{MgO}$ reacts with water to produce $\mathrm{Mg}(\mathrm{OH})_{2}$ with a loose structure, resulting in unsoundness and cracking. Among these uncracked test blocks, the highest $\mathrm{K}_{7}$ was only 0.58 , thus, 
incorporation of modifier was necessary.

Table 3 MOC mechanical properties

\begin{tabular}{cccccc}
\hline \multirow{2}{*}{ NO. } & \multirow{2}{*}{$\mathrm{MgO} / \mathrm{MgCl}_{2}$} & \multicolumn{2}{c}{ Compressive strength $\left(\mathrm{R}_{\mathrm{s}}\right) / \mathrm{MPa}$} & 7d-28d \\
& & $1 \mathrm{~d}$ & $7 \mathrm{~d}$ & $28 \mathrm{~d}$ & Strength decline/\% \\
\hline B-4 & 4 & 27.1 & 72.3 & 56.4 & 22 \\
B-5 & 5 & 31.8 & 68.9 & 60.6 & 12 \\
B-6 & 6 & 23.9 & 80.1 & 65.4 & 18 \\
B-7 & 7 & 25.9 & 64.5 & 58.8 & 9 \\
B-8 & 8 & 31.5 & 57.1 & ---- & ---- \\
B-9 & 9 & 29.9 & 52.3 & ---- & ---- \\
\hline
\end{tabular}

Table 4 MOC water resistance

\begin{tabular}{cccc}
\hline NO. & $\mathrm{MgO} / \mathrm{MgCl}_{2}$ & After soaking strength/MPa & $\mathrm{K}_{7}$ \\
\hline B-4 & 4 & 40.3 & 0.56 \\
B-5 & 5 & 37.2 & 0.54 \\
B-6 & 6 & 46.4 & 0.58 \\
B-7 & 7 & 34.4 & 0.53 \\
B-8 & 8 & cracked & ---- \\
B-9 & 9 & cracked & ---- \\
\hline
\end{tabular}

Select 6: 1: 13 as MOC mix design for the following modification test, the test results are shown in Table 5 and Table 6.

As showed in Table 5, $\mathrm{H}_{3} \mathrm{PO}_{4}$ prevented the strength decline of MOC between $7 \mathrm{~d}$ and $28 \mathrm{~d}$. The strength growth rate reached $79 \%$ when the dosage of $\mathrm{H}_{3} \mathrm{PO}_{4}$ was $1.2 \%$. Due to retarding effect caused by $\mathrm{H}_{3} \mathrm{PO}_{4}$, the hydration process and crystallization rate of MOC slow down, which lead to the decline of early strength. However, the retarding effect gives rise to crystal particles larger, thicker and denser, which is more beneficial to high strength at later stages.

As showed in Table 6, $\mathrm{H}_{3} \mathrm{PO}_{4}$ could improve MOC water resistance. When the dosage of $\mathrm{H}_{3} \mathrm{PO}_{4}$ was $1.0 \%$, the water resistance of MOC reached 0.82 , which was $41 \%$ higher than that of the blank group. The reason is similar to the influence of $\mathrm{H}_{3} \mathrm{PO}_{4}$ on mechanical properties. What is more, incorporation of $\mathrm{H}_{3} \mathrm{PO}_{4}$ made the $5 \cdot 1 \cdot 8$ phases transform from rod-shaped into gelatinous form, which weakened the destruction of water on the crystal phase.

Table 5 Effect of $\mathrm{H}_{3} \mathrm{PO}_{4}$ on mechanical properties of MOC

\begin{tabular}{|c|c|c|c|c|}
\hline \multirow{2}{*}{ NO. } & \multirow{2}{*}{$\mathrm{H}_{3} \mathrm{PO}_{4} / \%$} & \multicolumn{2}{|c|}{ Compressive strength $\left(\mathrm{R}_{\mathrm{s}}\right) / \mathrm{MPa}$} & \multirow{2}{*}{$\begin{array}{c}7 \mathrm{~d}-28 \mathrm{~d} \\
\text { strength decline/\% }\end{array}$} \\
\hline & & $7 d$ & $28 \mathrm{~d}$ & \\
\hline M-1 & 0.6 & 60.2 & 98.0 & 62.8 \\
\hline M-2 & 0.8 & 55.5 & 85.8 & 54.6 \\
\hline M-3 & 1.0 & 45.5 & 74.1 & 62.9 \\
\hline M-4 & 1.2 & 43.4 & 77.7 & 79.0 \\
\hline
\end{tabular}


Table 6 Effect of $\mathrm{H}_{3} \mathrm{PO}_{4}$ on water resistance of MOC

\begin{tabular}{ccccc}
\hline \multirow{2}{*}{ NO. } & \multirow{2}{*}{$\mathrm{H}_{3} \mathrm{PO}_{4} / \%$} & \multicolumn{2}{c}{ Compressive strength $\left(\mathrm{R}_{\mathrm{s}}\right) / \mathrm{MPa}$} & \multirow{2}{*}{$\mathrm{K}_{7}$} \\
\cline { 3 - 4 } & & before soaking & after soaking & \\
\hline M-1 & 0.6 & 60.2 & 42.9 & 0.71 \\
M-2 & 0.8 & 55.5 & 43.3 & 0.78 \\
M-3 & 1.0 & 45.5 & 37.3 & 0.82 \\
M-4 & 1.2 & 43.4 & 32.0 & 0.74 \\
\hline
\end{tabular}

The SEM images(Fig. 1) below show that $\mathrm{H}_{3} \mathrm{PO}_{4}$ can induce morphological changes of MOC hydration products.Before modification(Fig. 1(a)), the MOC hydration products are mostly needle-like,with a network structure and low density, which lead to poor water resistance;After modification(Fig. 1(b)), hydration products are mostly gelatinous form with dense distribution, which is favorable to water resistance.

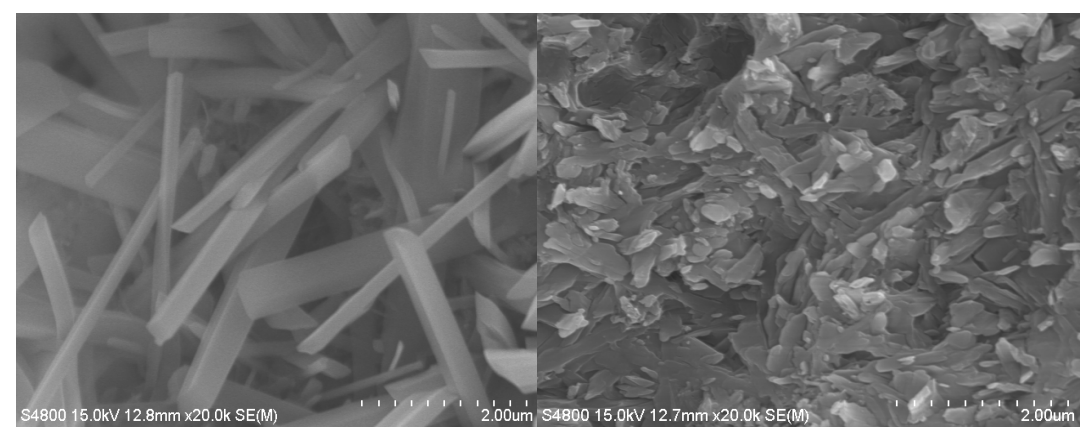

(a)

(b)

Fig. 1 Fracture morphology of samples before and after modification

Influence of cornstalks volume on composite materials. With the increasing volume of cornstalk fibers in the modified MOC, the apparent density of the composites gradually decreased. However, incorporation of cornstalk fibers had a limited effect on apparent density. When the volume ratio of cornstalk fibers was 2 , the workability of mixtures was deteriorated. What was worse, cornstalk fibers could not be completely wrapped by the paste, which was negative to the preparation process, mechanical properties and durability of test blocks. Unfortunately, large volume of cornstalk fibers showed little effect on the apparent density, which was still as high as $1485 \mathrm{~kg} / \mathrm{m}^{3}$.

As showed in Fig. 2(a), mechanical properties of the composites gradually decreased with the increasing of cornstalk fibers volume. Firstly, incorporation of cornstalk fibers destroy the original dense structure of MOC, and structural defects brought by cornstalk fibers are the principal factor on the destruction of test blocks. Secondly, cornstalk fibers play a major role in tractive effort, while it is not conducive to compressive strength.In the end, MOC paste is relatively reduced as the proportion of fibers increasing, which is adverse to compressive strength.

Perfect adhesion makes MOC and fibers form a high-intensity interface combination. Compared with rod-shaped cornstalk, the surface of the cornstalk fibers is rougher,which is favorable for the interface of MOC-cornstalk fibers.Three-dimensional distribution of cornstalk fibers in the MOC allows the transverse dispersion of the stress, reducing the risks of microcracks 
formation under stress. Therefore, cornstalk fibers improve the fracture toughness of composites.

As showed in Fig. 2(b), with the increasing volume of cornstalk fibers, bend-press ratio was elevated, displaying that the incorporation of cornstalk fibers improved the flexibility and crack resistance of composites. However, the specific strength gradually decreased, suggesting that the incorporation of cornstalk fibers did not make the material lightweight and high strength.

Combined with the workability of mixtures and the mechanical properties of test blocks, volume ratio of cornstalk 1.00 was selected for subsequent experiment.

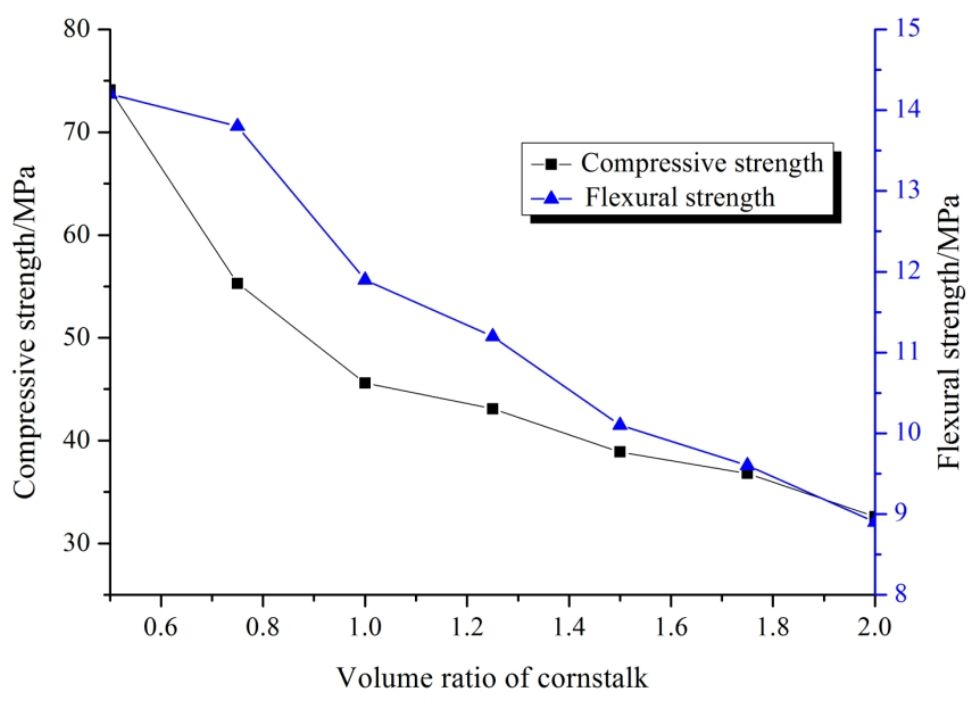

(a)

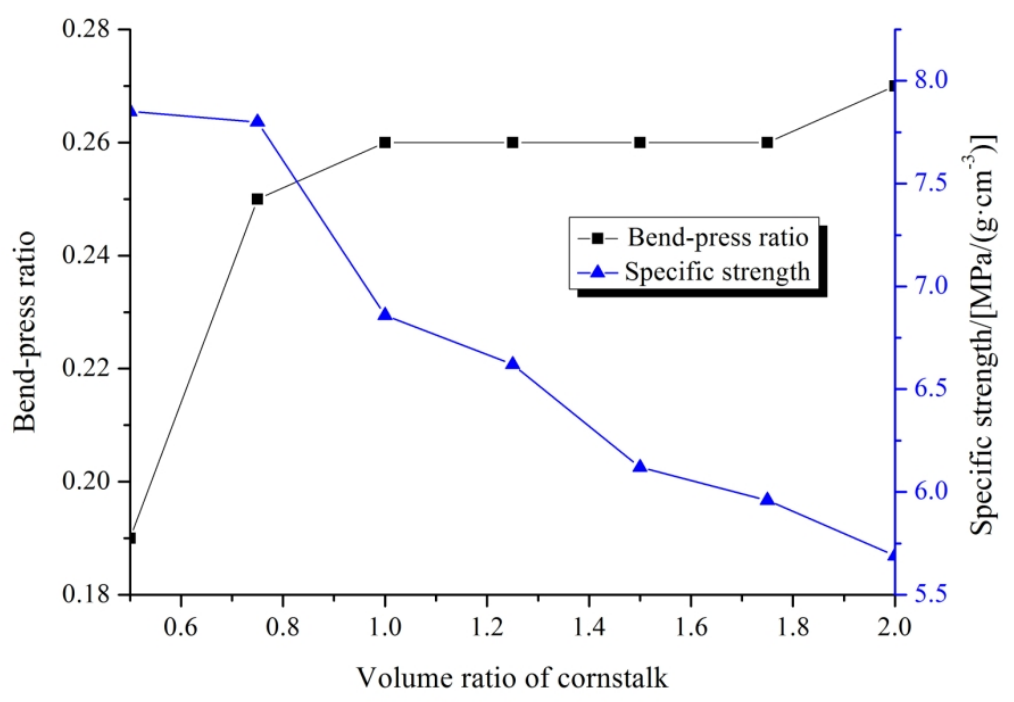

(b)

Fig. 2 Influence of cornstalk fibers volume on mechanical properties

\section{Conclusion}

Although MOC had the characteristic of high early strength, its strength decline at later stages; When $\mathrm{MgO} / \mathrm{MgCl}_{2} \geq 8$, too much $\mathrm{MgO}$ formed $\mathrm{Mg}(\mathrm{OH})_{2}$ with loose structure, resulting in 
unsoundness and cracking on test blocks; $\mathrm{H}_{3} \mathrm{PO}_{4}$ could not only improve the water resistance of MOC, but also solve the problem of strength decline; With the increasing volume of cornstalk fibers, bend-press ratio increased gradually, the flexibility and crack resistance of the composites improved, but the incorporation of cornstalk fibers on the apparent density was limited.

\section{References:}

[1] Q Fu, X G Huang and X D Liu. Research and trial production of small hollow block with cement straw and fly ash[J].Brick,2013,(03):33-36.

[2] Y A Li. Dissertation submitted for the degree of doctor of philosophy[D].South China University of Technology,2014.

[3] L Q Huang. A new method for modifying magnesium oxychloride cement[D].ShanTou University,2006.

[4] C Liu ,W X Wang, L L Zhang, L P Miu and A J Wang. Study on properties of materials core material of cement based composite thermal insulation board[J].Building Energy Saving,2013,(06):47-52.

[5] S L ABuLa. Study on the compound ecosystem thermal insulation wall panels and the physical and mechanical properties of cotton straw gypsum[D].Xinjiang Agricultural University, 2013.

[6] S Zhang and Z Ding. Research on composition and performance of phosphoric acid magnesium and expanded polystyrene granule insulating material[J].New Building Material,2013,(11):78-80.

[7] Y H Wang.Methods for improving the water resistance of magnesium oxychloride cement[N].China Building Materials News,2010-12-16(004). 